\title{
Impact of prosthesis-patient mismatch on late outcomes after bioprosthetic mitral valve replacement for mitral regurgitation
}

\author{
Yuichiro Kitada ${ }^{1}$, Mamoru Arakawa ${ }^{1}$, Homare Okamura $^{1}$, Kei Akiyoshi ${ }^{1}$, Daijiro Hori ${ }^{1}$, \\ Naoyuki Kimura ${ }^{1}$, and Atsushi Yamaguchi ${ }^{1}$ \\ ${ }^{1}$ Saitama Medical Center, Jichi Medical University
}

February 17, 2021

\begin{abstract}
Background and Aim of the Study: Negative impact of prosthesis-patient mismatch (PPM) on long term survival after valve replacement has been reported. However, the effect of PPM after bioprosthetic mitral valve replacement (MVR) has not yet been well examined. The purpose of this study was to investigate the effect of PPM on late outcomes after bioprosthetic MVR for mitral regurgitation (MR). Methods: A total of 181 patients underwent bioprosthetic MVR between April 2008 and December 2016. After excluding patients with mitral stenosis and those with incomplete data, 128 patients were included in the study. Postoperative transthoracic echocardiography was performed for all patients and the effective orifice area (EOA) was calculated using the pressure half-time method. The effective orifice area index (EOAI) was calculated by the formula: EOA/body surface area (BSA). PPM was defined as a postoperative EOAI [?] $1.2 \mathrm{~cm} 2 / \mathrm{m} 2$. The characteristics and outcomes were compared between the groups. Results: There were 34 patients (26.6\%) with PPM and 94 patients (73.4\%) without PPM. Although proportion of males and BSA were higher in the PPM group, valve size distributions were similar between the two groups. There were no significant differences in the in-hospital mortality and morbidities. Multivariable analysis showed that PPM was an independent predictor of late mortality (hazard ratio [HR] 3.38; 95\% confidence interval [CI] 1.69-6.75; p = .001) and death from heart failure (HR 31.03, 95\% CI 4.49-214.40, $\mathrm{p}<.001$ ). Conclusions: PPM after MVR for MR was associated with long-term mortality and death from heart failure.
\end{abstract}

\section{INTRODUCTION}

The phenomenon of prosthesis-patient mismatch (PPM), first described by Rahimtoola et al. in $1978,{ }^{1}$ is a condition in which the effective orifice area (EOA) of an implanted valve prosthesis does not match the patient's body size. Due to insufficient orifice area, PPM causes hemodynamics similar to valvular stenosis.

PPM after the aortic valve replacement has been well proven to be associated with higher incidences of longand short-term adverse outcomes. ${ }^{2,3}$ Insufficient orifice area in the left ventricular outflow causes increase in the left ventricular afterload, thus resulting in the left ventricular hypertrophy and diastolic dysfunction. Similar effect of PPM may be observed in the mitral position which may increase the afterload of the pulmonary circulatory system. Limited studies have evaluated the impact of PPM on the outcomes after mitral valve replacement (MVR). ${ }^{4-11}$ Further, most of these studies included both mitral stenosis (MS) and mitral regurgitation $(\mathrm{MR})$.

Considering the different hemodynamic background of MS and MR, PPM may have more negative impact on hemodynamic after MR. The purpose of this study was to investigate the effect of PPM on bioprosthetic valve replacement after MR.

\section{MATERIALS AND METHODS}

\subsection{Patient Population and Study Design}


Between March 2010 and June 2018, 181 consecutive patients who underwent MVR with a bioprosthetic valve were identified from the institutional database at Saitama Medical Center, Jichi Medical University. As per the inclusion criteria, we included patients who underwent bioprosthetic MVR with or without concomitant procedures. We excluded 53 patients in whom the dominant valve dysfunction was MS, and those without preoperative or postoperative echocardiographic data were missing. Finally, 128 patients were included. The patient's medical records were reviewed. Emergency surgery was defined as an operation performed within 24 hours of hospitalization.

Doppler transthoracic echocardiography was performed at discharge. The estimated EOA of the implanted mitral valve was calculated using the formula: 220/pressure half-time (PHT). The effective orifice area index (EOAI) was defined as the bioprosthetic EOA/body surface area (BSA), and PPM was defined as an EOAI was [?] $1.2 \mathrm{~cm}^{2} / \mathrm{m}^{2}$, as described in the previous report. ${ }^{12}$

Follow-up data were obtained from the clinical records or via telephone interview. The follow-up rate was 98.4\%; the patient status was confirmed in 126 patients at least 1 year postoperatively, excluding those who died within a year postoperatively. The mean follow-up period was $4.4 \pm 2.2$ years. The study protocol was approved by the Institutional Review Board of Jichi Medical University (January 15 2020, S19-123).

\subsection{Surgical Procedure}

Standard median sternotomy was performed. Cardiopulmonary bypass was established via cannulation of the ascending aorta, superior vena cava, and inferior vena cava. Antegrade and retrograde cold blood cardioplegia were administered intermittently. The mitral valve was approached via a right-sided left atrial (LA) incision. After resecting the anterior leaflet of the mitral valve, the diameter of the mitral annulus was measured using sizers provided by the manufacturers. The implanted valves included St Jude Medical Epic (St Jude Medical Inc., St Paul, MN, USA) in 72 (56.3\%), Magna Mitral (Edwards Lifescience, Irvine, CA, USA) in 35 (27.3\%), and Mosaic Mitral (Medtronic, Minneapolis, MN, USA) in 21 patients (16.4\%). Prosthesis selection was performed at the discretion of the surgeon.

\subsection{Statistical Analysis}

Categorical variables were expressed as frequencies and percentages. Continuous variables were expressed as the mean \pm standard deviation. The Fisher exact test was used to compare categorical variables, and the Student's t-test or the Mann-Whitney U-test was used to compare continuous variables. Overall survival and freedom from death from heart failure were analyzed using the Kaplan-Meier method. The log-rank test was used for intergroup comparisons.

Backward stepwise Cox proportional hazards regression analysis was used to determine the effect of perioperative variables on late mortality and death from heart failure. The variables analyzed included age, sex, BSA, the New York Heart Association (NYHA) 3/4, hypertension, diabetes, ischemic heart disease, pulmonary hypertension, chronic obstructive pulmonary disease, atrial fibrillation, cerebrovascular disease, chronic kidney disease (serum creatinine $>1.5 \mathrm{mg} / \mathrm{dL}$ ), hemodialysis, peripheral artery disease, prior cardiac surgery, preoperative left ventricular (LV) ejection fraction (EF), postoperative LA diameter, postoperative LV diastolic diameter, serum albumin, serum hemoglobin, endocarditis/prosthetic valve endocarditis (PVE), emergency and PPM at discharge. Variables showing $P<.20$ on univariable analysis were subjected to multivariable Cox proportional hazards regression analysis.

All statistical analyses were performed using the SPSS software version 25 (IBM Corp., Armonk, NY, USA). A $P$ value $<.05$ was considered statistically significant.

\section{RESULTS}

\subsection{Intergroup Comparison of Patient Characteristics and Operative Data}

Of the 128 patients, PPM was noted in 34 patients (26.6\%) at discharge. The baseline preoperative patient characteristics per group are shown in Table 1. Compared with the non-PPM group, the PPM group showed a higher proportion of males (PPM: 70.6\%, non-PPM: 46.8\%, $p=.027$ ), larger BSA (PPM: $1.60 \pm 0.18$, 
non-PPM: $1.48 \pm 0.17, p<.001$ ), a higher prevalence of cerebrovascular disease (PPM: $41.2 \%$, non-PPM: $22.3 \%, p=.044$ ), but a lower prevalence of endocarditis/PVE (PPM: 0\%, non-PPM: $17.0 \%, p=.006$ ). The operative data are shown in Table 2. There was no significant difference between the PPM and non-PPM patients regarding operative status and valve size distribution (Table 2). Implanted valve types were similar between the PPM and non-PPM patients (St Jude Medical Epic, $64.7 \%$ vs. 53.2\%, $p=.31$, Magna Mitral, $20.6 \%$ vs. $29.8 \%, p=.37$, Mosaic Mitral, $14.7 \%$ vs. $17.0 \%, p=1.000$ ). Everting mattress suture was used in 17 patients with PPM and 48 patients with non-PPM, whereas the non-everting mattress procedure was used in 17 patients with PPM and 46 patients with non-PPM $(p=1.000)$.

\subsection{Early Outcomes}

The in-hospital outcomes are presented in Table 3. The overall 30-day and in-hospital mortality did not differ between the groups (Overall 30-day mortality: $p=.27$, In hospital mortality: $p=.27$ ). No significant intergroup difference was observed in the rates of early morbidities (Table 3 ).

\subsection{Postoperative Echocardiographic Data}

Echocardiographic data are shown in Table 4. Compared with the non-PPM group, the PPM group had a significantly lower bioprosthetic mitral valve EOA (PPM: $1.6 \pm 0.2$, non-PPM: $2.6 \pm 0.6, p<.001$ ). The differences in the peak and mean pressure gradient between the PPM and non-PPM groups were not statistically significant (Peak pressure gradient: $17.2 \pm 8.5$ vs.14.8 $\pm 6.7, p=.11$, mean pressure gradient: $6.3 \pm 3.4$ vs. $5.5 \pm 2.9, p=.18$ ), though, interestingly, postoperative LA and LV diastolic diameters were significantly larger in the PPM group (LA diameter: $56 \pm 12$ vs. $50 \pm 10, p=.001$ ) (LV diastolic diameter: $55 \pm 8$ vs. $51 \pm 9, p=.031)$.

\subsection{Late Outcomes}

During the follow-up period, 40 patients died, indicating a 5 -year overall survival rate of $74.2 \%$ at 5 years. Of the late mortality cases, 15 patients belonged to the PPM group and 25 to the non-PPM group.

Kaplan-Meier analysis showed that the 5-year overall survival rate was 51.5\% in the PPM group and $74.8 \%$ in the non-PPM group ( $p=.034$, Figure 1A). The causes of death in the PPM group included heart failure (7 patients), cerebrovascular events ( 2 patients), malignancy (1 patient), unknown (2 patients), and others including pneumonia, renal failure, and superior mesenteric artery embolism (3 patients), whereas the causes in the non-PPM group included heart failure (2 patients), cerebrovascular events (3 patients), malignancy (1 patient), unknown (12 patients) and others including acute myocardial infarction, PVE, pneumonia, renal failure, respiratory failure ( 7 patients). The incidence of death from heart failure was significantly higher in the PPM group than the non-PPM group (PPM: 20.6\%, non-PPM: 2.1\%, $p=.001$ ), and Kaplan-Meier analysis showed that the 5-year freedom from death from heart failure rate was $72.9 \%$ in the PPM group and $97.3 \%$ in the non-PPM group $(p<.001$, Figure $1 \mathrm{~B})$

Valve-related events at follow-up occurred in 13 patients (10.2\%). These included structural valve deterioration (1 patient), nonstructural dysfunction (2 patients), embolism (6 patients), bleeding (2 patients), and PVE (2 patients) without intergroup differences $(p=.75)$.

\subsection{Predictors of Late Mortality and Death from Heart Failure}

Cox proportional hazards regression analysis was performed to determine the effect of PPM on late outcomes after MVR. Multivariable analysis showed that PPM was an independent predictor of late mortality (hazard ratio $[\mathrm{HR}]=3.38 ; 95 \%$ confidence interval $[\mathrm{CI}]=1.69-6.75, p=.001$, Figure $2 \mathrm{~A}$ ). Other predictors of late mortality included NYHA class 3/4, peripheral artery disease, and preoperative LV EF (Table 5). With regards to death from heart failure, PPM was also identified as an independent risk factor $(\mathrm{HR}=31.03$, $95 \% \mathrm{CI}=4.49-214.40, p<.001$, Figure 2B). Other independent predictors of death from heart failure were male, peripheral artery disease, and preoperative LV EF (Table 5).

\section{DISCUSSION}


The present study showed significant effect of PPM on long-term mortality and death from heart failure in patients undergoing bioprosthetic MVR for MR. Previous studies have also reported negative impact of PPM on long-term outcomes after MVR..$^{4-11}$ Lam et al. reported that PPM in the mitral position was associated with recurrence of heart failure and late mortality. ${ }^{6}$ In their cohort, postoperative PPM occurred more frequently in bioprosthetic MVR than in mechanical MVR $(57 \%$ vs. $23 \%, p<.001) .{ }^{6}$ However, their study included both MS and MR, which may have different impact from PPM. A study by LEE et al. have shown that PPM after MVR in patients with rheumatic MS had no influence on late clinical outcomes. ${ }^{13}$

Aziz et al. reported negative effect of PPM on long-term outcomes in patients receiving a bioprosthetic mitral valve. ${ }^{10}$ However, along with other previously reported studies, reference EOA was used to define PPM. ${ }^{6,8,10,11}$ There are three different techniques for calculating EOA: the use of reference EOA, continuity equation, and the PHT method. ${ }^{14}$ Reference EOA is a reference value provided by the manufacturer. This may not necessarily represent the actual EOA considering the different hemodynamics for each patient. The continuity equation method requires complex measurements on echocardiography, in which the measured values could vary among the examiners and may not be reproducible. Although measurements are influenced by chronotropic conditions and atrioventricular compliance, ${ }^{15}$ PHT method is the simplest and most reproducible method to calculate EOA. ${ }^{16,17}$

Magne et al. reported that moderate or severe PPM patients received prosthesis smaller than $27 \mathrm{~mm} .{ }^{7}$ However, our study suggested that the size of the mitral prosthesis was not necessarily associated with incidence of PPM. In the present study, 13 of the PPM patients (38.2\%) received prosthesis larger than $29 \mathrm{~mm}$. This may be explained by our postoperative echocardiography data which showed significantly larger LA and LV diastolic diameters in the PPM group compared to the non-PPM group. Given that LV contractility was the same between the two groups, increase in LV dimension may have led to increase in the transmitral blood volume resulting in prolonged PHT, thus showing PPM in the same size mitral prosthesis. ${ }^{18}$

PPM in the mitral position has been suggested to cause abnormally high residual transvalvular pressure gradients. This may lead to increase LA and pulmonary arterial pressures, subsequently resulting in heart failure. ${ }^{7}$ Further, mitral PPM has been reported to be an independent risk factor for persistence of pulmonary hypertension after MVR. ${ }^{15}$ Although our study showed no significant differences in pulmonary arterial pressures (PPM: $27 \pm 9 \mathrm{mmHg}$, non-PPM: $26 \pm 10 \mathrm{mmHg}, p=.69$ ), transvalvular peak pressure gradients (PPM: $17.2 \pm 8.5 \mathrm{mmHg}$, non-PPM: $14.8 \pm 6.7 \mathrm{mmHg}, p=.11$ ) and mean pressure gradients (PPM: $6.3 \pm$ $3.4 \mathrm{mmHg}$, non-PPM: $5.5 \pm 2.9 \mathrm{mmHg}, p=.18$ ) between the two groups, this may be due to the timing of the echocardiography. Postoperative echocardiography in the present study was performed approximately a week after the operation in which the patients were mostly at rest in the hospital. Previous study has shown that the mean transvalvular pressure gradient increased from $5 \pm 2$ to $8 \pm 3 \mathrm{mmHg}$ after exercise in patients with a prosthetic mitral valve. Further, the pulmonary artery systolic pressure increased with exercise from $28 \pm 8$ to $39 \pm 15 \mathrm{mmHg} .{ }^{19}$ Physical activity in most patients usually increases after discharge, thus the effect of insufficient EOAI on transvalvular pressure gradient and pulmonary artery systolic pressure may be influenced more at long term after surgery. Given that PPM was the predictor of heart failure and overall late death in our study, it may be important to follow-up PPM patients closely, to monitor the changes in the LA and pulmonary artery systolic pressure.

\subsection{Study Limitations}

The limitations of our study that need to be addressed. First, this was a single-center retrospective study with a small sample size. Second, in this study, we estimated the EOA using the PHT. There are several methods that can be used to calculate the EOA, and, depending on the cases, the PHT may not accurately reflect the actual EOA, which can result in an inaccurate diagnosis of PPM. Third, because this study did not have a randomized design, it is possible that unidentified confounders or selection bias may have influenced the results. Fourth, the preoperative values of the LA and LV diastolic diameters could not be obtained in several patients. Thus, further prospective studies are necessary to determine the impact of PPM on late outcomes. 


\section{CONCLUSIONS}

Our study indicated that PPM after bioprosthetic MVR in MR patients was associated with worse late outcomes including heart failure. Further, use of large valves may not necessarily prevent PPM. Diagnosis of PPM should be performed postoperatively using echocardiography and patients with PPM should be follow up more closely to monitor changes in their pulmonary artery pressure and to detect early sign of heart failure.

\section{AUTHOR CONTRIBUTIONS}

Conception of the work: Mamoru Arakawa, Daijiro Hori. Analysis and interpretation of data: Mamoru Arakawa, Yuichiro Kitada. Data collection: Mamoru Arakawa, Yuichiro Kitada, Kei Akiyoshi. Drafting of the manuscript: Yuichiro Kitada. Critical revision of the manuscript: Homare Okamura, Naoyuki Kimura. Approval of article: Atsushi Yamaguchi.

Table 1. Preoperative patient characteristics per study group

\begin{tabular}{|c|c|c|c|c|}
\hline Variable & Total $(n=128)$ & $\operatorname{PPM}(n=34)$ & $\begin{array}{l}\text { Non-PPM }(n= \\
94)\end{array}$ & $P$-value \\
\hline Age (years) & $75.2 \pm 7.2$ & $76.2 \pm 5.3$ & $74.9 \pm 7.7$ & .37 \\
\hline Male & $68(53.1 \%)$ & $24(70.6 \%)$ & $44(46.8 \%)$ & .027 \\
\hline $\begin{array}{l}\text { Body surface area } \\
\left(\mathrm{m}^{2}\right)\end{array}$ & $1.51 \pm 0.18$ & $1.60 \pm 0.18$ & $1.48 \pm 0.17$ & $<.001$ \\
\hline NYHA class $3 / 4$ & $64(50.0 \%)$ & $12(35.3 \%)$ & $52(55.3 \%)$ & .071 \\
\hline Hypertension & $72(56.3 \%)$ & $23(67.6 \%)$ & $49(52.1 \%)$ & .16 \\
\hline Diabetes & $20(15.6 \%)$ & $6(17.7 \%)$ & $14(14.9 \%)$ & .78 \\
\hline $\begin{array}{l}\text { Ischemic heart } \\
\text { disease }\end{array}$ & $20(15.6 \%)$ & $4(11.8 \%)$ & $16(17.0 \%)$ & .59 \\
\hline $\begin{array}{l}\text { Pulmonary } \\
\text { hypertension }\end{array}$ & $65(50.8 \%)$ & $19(55.9 \%)$ & $46(48.9 \%)$ & .55 \\
\hline COPD & $7(5.5 \%)$ & $0(0 \%)$ & $7(7.4 \%)$ & .19 \\
\hline Atrial fibrillation & $46(35.9 \%)$ & $12(35.3 \%)$ & $34(36.2 \%)$ & 1.000 \\
\hline $\begin{array}{l}\text { Cerebrovascular } \\
\text { disease }\end{array}$ & $35(27.3 \%)$ & $14(41.2 \%)$ & $21(22.3 \%)$ & .044 \\
\hline $\begin{array}{l}\text { Chronic kidney } \\
\text { disease }^{\mathrm{a}}\end{array}$ & $14(10.9 \%)$ & $5(14.7 \%)$ & $9(9.6 \%)$ & .52 \\
\hline Hemodialysis & $2(1.6 \%)$ & $0(0 \%)$ & $2(2.1 \%)$ & 1.000 \\
\hline $\begin{array}{l}\text { Peripheral artery } \\
\text { disease }\end{array}$ & $3(2.3 \%)$ & $1(2.9 \%)$ & $2(2.1 \%)$ & 1.000 \\
\hline $\begin{array}{l}\text { Prior cardiac } \\
\text { surgery }\end{array}$ & $22(17.2 \%)$ & $4(11.8 \%)$ & $18(19.2 \%)$ & .43 \\
\hline $\begin{array}{l}\text { Preoperative } \\
\text { LVEF (\%) }\end{array}$ & $58.0 \pm 12.9$ & $58.2 \pm 12.6$ & $57.9 \pm 13.1$ & .94 \\
\hline $\begin{array}{l}\text { Serum albumin } \\
(\mathrm{g} / \mathrm{dL})\end{array}$ & $3.7 \pm 0.7$ & $3.8 \pm 0.7$ & $3.6 \pm 0.7$ & .16 \\
\hline $\begin{array}{l}\text { Serum } \\
\text { hemoglobin } \\
(\mathrm{g} / \mathrm{dL})\end{array}$ & $11.6 \pm 2.2$ & $11.7 \pm 2.2$ & $11.6 \pm 2.2$ & .89 \\
\hline Endocarditis/PVE & $16(12.5 \%)$ & $0(0 \%)$ & $16(17.0 \%)$ & .006 \\
\hline
\end{tabular}

Note: Values are expressed as mean \pm standard deviation or $n(\%)$.

Abbreviations: $C O P D$, chronic obstructive pulmonary disease; $L V E F$, left ventricular ejection fraction; 
NYHA, New York Heart Association; PVE , prosthesis valve endocarditis.

${ }^{\text {a }}$ Serum creatinine $>1.5 \mathrm{mg} / \mathrm{dl}$.

Table 2. Intraoperative data per study group

\begin{tabular}{|c|c|c|c|c|c|}
\hline Variable & $\begin{array}{l}\text { Total }(n= \\
128)\end{array}$ & $\mathrm{PPM}(n=34)$ & $\begin{array}{l}\text { Non-PPM }(n \\
=94)\end{array}$ & $\begin{array}{l}\text { Non-PPM }(n \\
=94)\end{array}$ & $P$-value \\
\hline $\begin{array}{l}\text { Operative } \\
\text { status }\end{array}$ & $\begin{array}{l}\text { Operative } \\
\text { status }\end{array}$ & $\begin{array}{l}\text { Operative } \\
\text { status }\end{array}$ & $\begin{array}{l}\text { Operative } \\
\text { status }\end{array}$ & $\begin{array}{l}\text { Operative } \\
\text { status }\end{array}$ & $\begin{array}{l}\text { Operative } \\
\text { status }\end{array}$ \\
\hline Elective & $109(85.2 \%)$ & $31(91.2 \%)$ & $31(91.2 \%)$ & $78(83.0 \%)$ & .40 \\
\hline Emergent & $19(14.8 \%)$ & $3(8.8 \%)$ & $3(8.8 \%)$ & $16(17.0 \%)$ & .40 \\
\hline $\begin{array}{l}\text { Cardiopulmonary } \\
\text { bypass time } \\
\text { (min) }\end{array}$ & $172 \pm 58$ & $183 \pm 54$ & $183 \pm 54$ & $168 \pm 59$ & .20 \\
\hline $\begin{array}{l}\text { Aortic } \\
\text { cross-clamp } \\
\text { time (min) }\end{array}$ & $140 \pm 48$ & $150 \pm 42$ & $150 \pm 42$ & $137 \pm 50$ & .17 \\
\hline $\begin{array}{l}\text { Concomitant } \\
\text { procedures }\end{array}$ & $\begin{array}{l}\text { Concomitant } \\
\text { procedures }\end{array}$ & $\begin{array}{l}\text { Concomitant } \\
\text { procedures }\end{array}$ & $\begin{array}{l}\text { Concomitant } \\
\text { procedures }\end{array}$ & $\begin{array}{l}\text { Concomitant } \\
\text { procedures }\end{array}$ & $\begin{array}{l}\text { Concomitant } \\
\text { procedures }\end{array}$ \\
\hline $\begin{array}{l}\text { Coronary } \\
\text { artery bypass } \\
\text { grafting }\end{array}$ & $11(8.6 \%)$ & $3(8.8 \%)$ & $3(8.8 \%)$ & $8(8.5 \%)$ & 1.000 \\
\hline $\begin{array}{l}\text { Maze } \\
\text { procedure }\end{array}$ & $24(18.8 \%)$ & $6(17.6 \%)$ & $6(17.6 \%)$ & $18(19.1 \%)$ & 1.000 \\
\hline $\begin{array}{l}\text { Tricuspid } \\
\text { annuloplasty }\end{array}$ & $86(67.2 \%)$ & $24(70.6 \%)$ & $24(70.6 \%)$ & $62(66.0 \%)$ & .68 \\
\hline AAR/TAR & $11(8.6 \%)$ & $4(11.8 \%)$ & $4(11.8 \%)$ & $7(7.5 \%)$ & .48 \\
\hline Myectomy & $5(3.9 \%)$ & $2(5.9 \%)$ & $2(5.9 \%)$ & $3(3.4 \%)$ & .61 \\
\hline $\begin{array}{l}\text { Prosthesis size } \\
\text { distribution }\end{array}$ & $\begin{array}{l}\text { Prosthesis size } \\
\text { distribution }\end{array}$ & $\begin{array}{l}\text { Prosthesis size } \\
\text { distribution }\end{array}$ & $\begin{array}{l}\text { Prosthesis size } \\
\text { distribution }\end{array}$ & $\begin{array}{l}\text { Prosthesis size } \\
\text { distribution }\end{array}$ & $\begin{array}{l}\text { Prosthesis size } \\
\text { distribution }\end{array}$ \\
\hline $23 \mathrm{~mm}$ & $9(7.0 \%)$ & $2(5.9 \%)$ & $2(5.9 \%)$ & $7(7.5 \%)$ & 1.000 \\
\hline $25 \mathrm{~mm}$ & $31(24.2 \%)$ & $7(20.6 \%)$ & $7(20.6 \%)$ & $24(25.6 \%)$ & .65 \\
\hline $27 \mathrm{~mm}$ & $39(30.5 \%)$ & $12(35.3 \%)$ & $12(35.3 \%)$ & $27(28.7 \%)$ & .52 \\
\hline $29 \mathrm{~mm}$ & $31(24.2 \%)$ & $6(17.6 \%)$ & $6(17.6 \%)$ & $25(26.6 \%)$ & .36 \\
\hline $31 \mathrm{~mm}$ & $18(14.1 \%)$ & $7(20.6 \%)$ & $7(20.6 \%)$ & $11(11.7 \%)$ & .25 \\
\hline
\end{tabular}

Note: Values are expressed as mean \pm standard deviation or $n(\%)$.

Abbreviations: $A A R$, ascending aortic replacement; $T A R$, total arch replacement.

Table 3. In-hospital outcomes per study group

\begin{tabular}{|c|c|c|c|c|}
\hline Variable & Total $(n=128)$ & $\operatorname{PPM}(n=34)$ & $\begin{array}{l}\text { Non-PPM }(n= \\
94)\end{array}$ & $P$-value \\
\hline 30-day mortality & $1(0.8 \%)$ & $1(2.9 \%)$ & $0(0 \%)$ & .27 \\
\hline $\begin{array}{l}\text { In-hospital } \\
\text { mortality }\end{array}$ & $1(0.8 \%)$ & $1(2.9 \%)$ & $0(0 \%)$ & .27 \\
\hline Stroke & $2(1.6 \%)$ & $1(2.9 \%)$ & $1(1.1 \%)$ & .46 \\
\hline $\begin{array}{l}\text { Re-exploration for } \\
\text { bleeding }\end{array}$ & $5(3.9 \%)$ & $1(2.9 \%)$ & $4(4.3 \%)$ & 1.000 \\
\hline $\begin{array}{l}\text { New onset of } \\
\text { atrial fibrillation }\end{array}$ & $21(16.4 \%)$ & $5(14.7 \%)$ & $16(17.0 \%)$ & 1.000 \\
\hline
\end{tabular}


Prolonged

$13(10.2 \%)$

$6(17.6 \%)$

$7(7.5 \%)$

.11

ventilation use

$>48$ hours

Note: Values are expressed as $n(\%)$.

Table 4. Postoperative echocardiographic data

\begin{tabular}{|c|c|c|c|c|}
\hline Variable & Total $(n=128)$ & $\mathrm{PPM}(n=34)$ & $\begin{array}{l}\text { Non-PPM }(n= \\
94)\end{array}$ & $P$-value \\
\hline $\begin{array}{l}\text { Left atrial } \\
\text { diameter }(\mathrm{mm})\end{array}$ & $52 \pm 11$ & $56 \pm 12$ & $50 \pm 10$ & .001 \\
\hline $\begin{array}{l}\text { Left ventricle } \\
\text { diastolic diameter } \\
(\mathrm{mm})\end{array}$ & $52 \pm 9$ & $55 \pm 8$ & $51 \pm 9$ & .031 \\
\hline $\begin{array}{l}\text { Left ventricle } \\
\text { systolic diameter } \\
(\mathrm{mm})\end{array}$ & $37 \pm 10$ & $38 \pm 8$ & $37 \pm 11$ & .43 \\
\hline $\begin{array}{l}\text { Mitral peak } \\
\text { pressure gradient } \\
(\mathrm{mmHg})\end{array}$ & $15.5 \pm 7.2$ & $17.2 \pm 8.5$ & $14.8 \pm 6.7$ & .11 \\
\hline $\begin{array}{l}\text { Mitral mean } \\
\text { pressure gradient } \\
(\mathrm{mmHg})\end{array}$ & $5.8 \pm 3.0$ & $6.3 \pm 3.4$ & $5.5 \pm 2.9$ & .18 \\
\hline $\begin{array}{l}\text { Systolic } \\
\text { pulmonary } \\
\text { arterial pressure } \\
(\mathrm{mmHg})\end{array}$ & $26 \pm 10$ & $27 \pm 9$ & $26 \pm 10$ & .69 \\
\hline $\begin{array}{l}\text { Pressure half time } \\
(\mathrm{sec})\end{array}$ & $102 \pm 30$ & $134 \pm 27$ & $91 \pm 22$ & $<.001$ \\
\hline $\begin{array}{l}\text { Effective orifice } \\
\text { area }\left(\mathrm{cm}^{2}\right)\end{array}$ & $2.3 \pm 0.7$ & $1.6 \pm 0.2$ & $2.6 \pm 0.6$ & $<.001$ \\
\hline $\begin{array}{l}\text { Effective orifice } \\
\text { area index } \\
\left(\mathrm{cm}^{2} / \mathrm{m}^{2}\right)\end{array}$ & $1.6 \pm 0.6$ & $1.0 \pm 0.1$ & $1.8 \pm 0.5$ & $<.001$ \\
\hline
\end{tabular}

Note: Values are expressed as mean \pm standard deviation.

Table 5. Cox proportional hazards analysis for independent risk factors for late mortality and death from heart failure

\begin{tabular}{llll}
\hline & Univariable & & Multivariable \\
Variable & HR (95\% CI) & P-value & HR (95\% CI) \\
Late mortality & Late mortality & Late mortality & Late mortality \\
NYHA class 3/4 & $3.69(1.80-7.56)$ & $<.001$ & $4.08(1.85-8.98)$ \\
Peripheral artery disease & $8.21(2.46-27.37)$ & .001 & $7.05(2.02-24.64)$ \\
Preoperative LVEF(\%) & $0.96(0.93-0.98)$ & $<.001$ & $0.97(0.95-0.99)$ \\
PPM & $1.97(1.04-3.75)$ & .038 & $3.38(1.69-6.75)$ \\
Death from heart failure & Death from heart failure & Death from heart failure & Death from heart failure \\
male & $0.27(0.06-1.28)$ & .10 & $0.10(0.02-0.61)$ \\
Peripheral artery disease & $13.14(1.51-114.37)$ & .002 & $38.86(1.52-990.50)$
\end{tabular}




\begin{tabular}{llll} 
Preoperative LVEF(\%) & $0.92(0.87-0.97)$ & .001 & $0.90(0.84-0.97)$ \\
PPM & $5.63(1.65-19.29)$ & .006 & $31.03(4.49-214.40)$ \\
\hline
\end{tabular}

Abbreviation: $C I$, confidence interval; $H R$, hazard ratio; $L V E F$, Left ventricular ejection fraction; $N Y H A$ , New York Heart Association; PPM, patient-prosthesis mismatch.

\section{References}

1. Rahimtoola SH. The problem of valve prosthesis-patient mismatch. Circulation 1978;58:20-24.

2. Hong S, Yi G, Youn YN, et al. Effect of the prosthesis-patient mismatch on long-term clinical outcomes after isolated aortic valve replacement for aortic stenosis: a prospective observational study. J Thorac Cardiovasc Surg 2013;146:1098-1104.

3. Guo L, Zheng J, Chen L, et al. Impact of prosthesis-patient mismatch on short-term outcomes after aortic valve replacement: a retrospective analysis in East China. J

Cardiothorac Surg 2017;12:42.

4. Yazdanbakhsh AP, van den Brink RB, Dekker E, et al. Small valve area index: its influence on early mortality after mitral valve replacement. Eur J Cardiothorac Surg 2000;17:222-227.

5. Ruel M, Rubens FD, Masters RG, et al. Late incidence and predictors of persistent or recurrent heart failure in patients with mitral prosthetic valves. J Thorac

Cardiovasc Surg 2004;128:278-283.

6. Lam BK, Chan V, Hendry P, et al. The impact of patient prosthesis mismatch on late outcomes after mitral valve replacement. J Thorac Cardiovasc Surg 2007;133:1464-1473.

7. Magne J, Mathieu P, Dumesnil JG, et al. Impact on prosthesis-patient mismatch on survival after mitral valve replacement. Circulation 2007;115:1417-1425.

8. Jamieson WR, Gemann E, Ye J, et al. Effect of prosthesis-patient mismatch on longterm survival with mitral valve replacement: assessment to 15 years. Ann Thorac Surg 2008;87:1135-1141.

9. Shi WY, Yap CH, Hayward PA, et al. Impact of prosthesis-patient mismatch after mitral valve replacement: a multicenter analysis of early outcomes and midterm survival. Heart 2011;97:1074-1081.

10. Aziz A, Lawton JS, Maniar HS, et al. Factors affecting survival after mitral valve replacement in patients with prosthesis-patient mismatch. Ann Thorac Surg 2010;90:1202-1210.

11. Akuffu AM, Zhao H, Zheng J, et al. Prosthesis-patient mismatch after mitral valve replacement: a single-centered retrospective analysis in East China. J

Cardiothorac Surg 2018;13:100. 
12. Pibarot P, Dumesnil JG. Prosthesis-patient mismatch in the mitral position: old concept, new evidence. J Thorac Cardiovasc Surg 2007;133:1405-1408.

13. Lee SH, Chang BC, Youn YN, et al. Impact of prosthesis-patient mismatch after mitral valve replacement in rheumatic population: Does mitral position prosthesispatient mismatch really exist? J Cardiothorac Surg 2017;12:88.

14. Cho IJ, Hong GR, Lee SH, et al. Prosthesis-patient mismatch after mitral valve replacement: comparison of different methods of effective orifice area calculation.

Yonsei Med J 2016;57:328-336.

15. Li M, Dumesnil JG, Mathieu P, et al. Impact of valve prosthesis-patient mismatch on pulmonary arterial pressure after mitral valve replacement. J Am Coll Cardiol 2005;45:1034-1040.

16. Hatle L, Angelsen B, Tomsdal A. Noninvasive assessment of atrioventricular pressure half time by Doppler ultrasound. Circulation 1979;60:1096-1104.

17. Smith MD, Handshoe R, Handshoe S, et al. Comparative accuracy of twodimensional echocardiography and Doppler pressure half-time methods in assessing severity of mitral stenosis in patients with and without prior commissurotomy. Circulation 1986;73:100-107.

18. Gülch RW, Jacob R. Geometric and muscle physiological determinants of cardiac stroke volume as evaluated on the basis of model calculations. Basic Res Cardiol 1988;83:476-485.

19. Leavitt J I, Coats M H, Falk R H. Effects of exercise on transmitral gradient and pulmonary artery pressure in patients with mitral stenosis or a prosthetic mitral valve: A doppler echocardiographic study. J Am Coll Cardiol 1991;17:1520-1526.

\section{Figure Legends}

Figure 1. (A) Kaplan-Meier curves showing survival probability after MVR in patients with PPM and non-PPM. $P$ - values were obtained using the log-rank test.

(B) Kaplan-Meier curves showing probability of freedom from death from heart failure after MVR in patients with PPM and non-PPM.P- values were obtained using the log-rank test.

Abbreviations: $P P M$, prosthesis-patient mismatch; $M V R$, mitral valve replacement

Figure 2. (A) Risk-adjusted Kaplan-Meier curves showing survival probability after MVR in patients with PPM and non-PPM.P-values were obtained using the cox proportional hazards regression analysis.

(B) Risk-adjusted Kaplan-Meier curves showing probability of freedom from death from heart failure after MVR in patients with PPM and non-PPM. $P$ - values were obtained using the cox proportional hazards regression analysis.

Abbreviations: $P P M$, prosthesis-patient mismatch; $M V R$, mitral valve replacement 
(A)

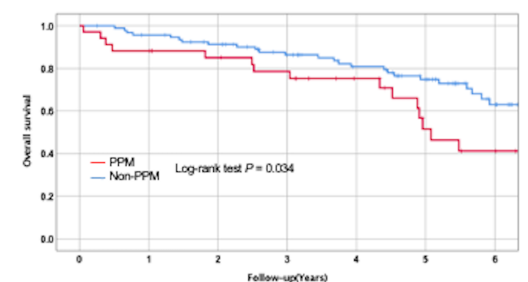

No. at risk

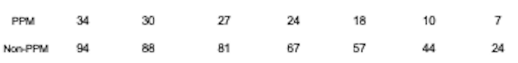

(B)

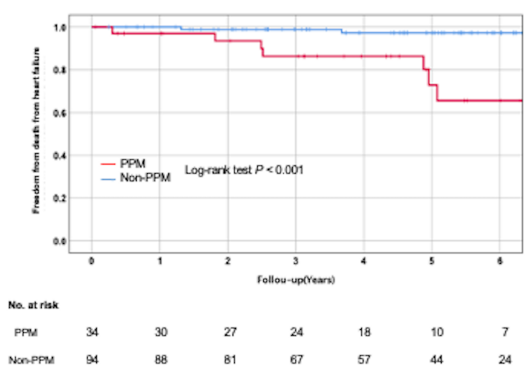


(A)

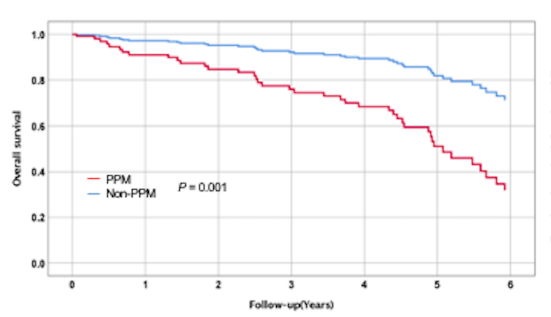

(B)

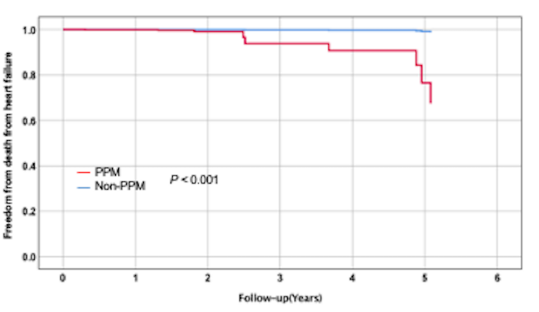

